\title{
Formação Continuada e Certificação de Professores ${ }^{1}$
}

\author{
Carlos Roberto Jamil CURY*
}

\section{FUNDAMENTAÇÃO}

O Sistema Nacional de Formação Continuada e Certificação de Professores não é uma questão que possa se tratada sem que a ela corresponda um certo grau de fundamentação.

Embora se possa dizer, genericamente, que uma profissão se qualifica por tudo que se promova em favor dela é preciso distinguir a formação de outros processos com igual horizonte.

A qualificação é uma relação social que envolve o coletivo e a relação entre educação e trabalho. Como em toda profissão, essa relação possui uma dimensão formativa inicial: aquela que possibilita a uma categoria o exercício profissional. No caso dos docentes, a formação inicial completa em estabelecimentos regulares e credenciados é uma licença que, por sua vez, faz do seu portador, e só dele, alguém capaz de ingressar nas redes de educação escolar dos sistemas de ensino. Portanto, a qualificação implica uma formação sistemática, regular e regulamentada, que, quando obtida em estabelecimentos escolares reconhecidos, gera um diploma ao seu portador. Ela tem um caráter coletivo e institucional.

A certificação, por sua vez, tem um pólo diferente, que é o indivíduo, a pessoa singular, aquele(a) profissional já em exercício na docência dos estabelecimentos escolares dos sistemas de ensino. Ela responde à necessidade de avaliar se o grau explicitação e organização em que se encontra o saber individual adquirido no fazer profissional, é suficiente para permitir sua socialização. Quando o indivíduo passa pelo processo de obtenção de um certificado, o Sistema de Certificação autentica os saberes que têm sua base nos fazeres do cotidiano profissional. Portanto, esses saberes necessitam de condições para

\footnotetext{
${ }^{1}$ Palestra proferida aos integrantes da Rede Nacional de Formação de Professores por ocasião do lançamento do Convênio. Brasília, 26/05/2004.

* Pós-Doutor pela Universidade de São Paulo - USP. Pós-Doutor pela Universite de Paris V (Rene Descartes), U.P. V, Paris, França. Professor Adjunto da Pontifícia Universidade Católica de Minas Gerais - PUC-MG.
}

Olhar de professor, Ponta Grossa, 7(1): 187-193, 2004. 
se verem dotados de um caráter sistemático. E este novo caráter nem sempre é obtido exclusivamente por meios autodidatas. É para isso que existe a formação processual, contínua, ou seja, a formação continuada.

Nesse sentido, importa não tratar sociedade e indivíduo como elementos antagônicos, mas sim como pólos de uma dialética maior. E não se deve reificar a qualificação na sua dimensão sócio-institucional dada pela formação inicial como se o professor ou a professora, ao longo da sua vida profissional, não construísse novos saberes, como se aquele saber atestado pelo diploma de conclusão do curso fosse suficiente para o pleno exercício profissional.

Por melhor e mais avançado que seja um curso de formação acadêmica, o professor, como qualquer profissional, não sai "pronto" da universidade, mas tem necessidade de complementar, aprimorar e atualizar seus conhecimentos, na prática. Na perspectiva da Epistemologia contemporânea, a prática não constitui mero campo de aplicação da teoria aprendida na universidade, pois o conhecimento se produz também na própria prática.

Assim, formação inicial e continuada fazem parte de um processo contínuo que forma o profissional da educação e, ao mesmo tempo, a profissão de educador e a própria escola. Ambas as dimensões - inicial e continuada - apoiamse em princípios e pressupostos comuns, considerando o aluno/professor como sujeito, valorizando suas experiências pessoais e seus saberes da prática. Apoiam-se no trabalho coletivo e compartilhado, mas isso não exclui, ao contrário, exige, o desenvolvimento e o compromisso individuais.

Além disso, no atual contexto de produção cada vez mais acelerada de conhecimentos científicos, não se pode esquecer a importância da atualização permanente, de forma a democratizar o acesso de todos os profissionais aos progressos do seu campo de trabalho.

Assim, tomar a formação inicial docente em si, com suas precariedades e virtudes, como fonte para analisar, criticar, elogiar, avaliar enfim a atuação dos docentes em exercício na educação básica é incorrer no erro lógico de tomar uma manifestação importante e significativa como se ela fosse o todo. Logicamente, qualquer avaliador sabe que a formação inicial é a condição e o meio mais próximo e direto para o exercício profissional em sala de aula. Portanto, ela deve ser a melhor possível e a mais adequada ao perfil dos estudantes de modo que o princípio do acesso e permanência na escola dos estudantes seja o mais universal e também o melhor.

Entretanto, os saberes nascidos do fazer também têm de ser objeto de valorização sistemática, o que nem sempre acontece. O momento dessa valorização implica uma iniciativa que possibilite uma organização mais clara e mais sistemática que signifique um momento de retomada e de reflexão de experiências e questionamento de rotinas. A formação continuada permite, então, que o

$\overline{188}$ Olhar de professor, Ponta Grossa, 7(1): 187-193, 2004. 
professor vá se apropriando como sujeito dos conhecimentos que ele mesmo geroue que se torne um professor investigador que pode rever sua prática, atribuir-lhe novos significados e obter maior espaço para a compreensão das mudanças que o atingem. Além disso, os desafios atuais do mundo contemporâneo implicam um conhecimento teórico-prático de uma sociedade em que a sala de aula se projeta, por exemplo pela rede mundial de computadores, para além das quatro paredes.

Caso o sujeito queira autenticar, tornar certo estes conhecimentos reelaborados ele pode recorrer à certificação. Trata-se, pois, de um momento da identificação e do reconhecimento do mérito individual. O processo de certificação, a depender da vontade dos indivíduos, se volta para a autenticação deste último momento de um movimento processual.

Entretanto esses conceitos e essa discussão necessitam, no Brasil, de uma saturação histórica para ganhar novos contornos, identificar limites e ver possibilidades.

\section{HISTÓRICO}

Sabe-se que até os anos 1960, havia uma espécie de simetria entre classe social, socialização familiar e socialização escolar dos professores e dos estudantes. Os perfís socioeconômicos e culturais dos sujeitos envolvidos na relação pedagógica eram próximos. Eventuais lacunas no processo de socialização escolar podiam ser preenchidas pela socialização familiar. Essa última contava com materiais e situações pedagógicas e culturais tais como bibliotecas, incentivo à leitura, diversificação cultural, experiências extra-escolares, controle do aprendizado em casa, entre outros.

Paralelamente, os docentes da Escola Normal eram contratados por meio de concursos públicos, para cujo alvo importava fazer um caminho precursor onde era importante "estagiar" junto a um outro professor sênior até chegar à condição de "titular da cadeira". Assim, as Escolas Normais se habilitavam a bem preparar os futuros docentes do ensino primário. Além disso, o salário dos professores - mormente os secundários - gozava de razoável poder aquisitivo, mesmo porque a femininização da profisssão se fazia concomitante ao apoio familiar ou conjugal. Isto permitia um período de trabalho direto e um período indireto voltado para preparação de aulas e correção de trabalhos.

Comumente, os destinatários do sistema escolar, em todos os níveis eram os filhos das classes médias e das classes altas.

Na ditadura pós-64, o Brasil passou por um grande processo de industrialização e de urbanização. Os quatro anos da então escola primária obrigatória tornaram-se insuficientes. Era preciso estender para oito e assim o fez a Cons-

Olhar de professor, Ponta Grossa, 7(1): 187-193, 2004. 
tituição de 1967. No entanto, esse processo de modernização trouxe levas de migrantes da zona rural e do interior que provocaram o crescimento rápido e desordenado das grandes cidades. Tais cidadãos necessitavam do ensino fundamental, ainda então denominado ensino primário. Para isso, era preciso construir escolas, expandir a rede física, mas nesse momento, a Constituição Brasileira não vinculava recursos para a educação como ocorria com as as Cartas Magnas de 1934 e 1946 e ocorre na atual, de 1988. É certo que esta vinculação foi restabelecida em 1969, na Emenda Constitucional da Junta Militar, apenas para os Municípios. Mas, como já era tradicional, os Municípios ficavam com a menor parte da arrecadação tributária. Com isto a tese da municipalização, em um contexto de profundo desequilíbrio federativo nas disparidades regionais, na distribuição de impostos e na desigualdade social, resultou em precarização da oferta do ensino obrigatório. Entretanto, a demanda continua a existir. De onde tirar o dinheiro para a construção das escolas a fim de atender à expansão da demanda? Um recurso usado foi o do achatamento salarial dos professores. Os professores, de cujos salários saíram boa parte das fontes de financiamento da expansão da rede física dos estabelecimentos do já então ensino de primeiro grau, de lá para cá, nunca tiveram a devida reparação financeira. Salários deprimidos implicaram a dupla ou tripla jornada de trabalho, para recomposição do poder aquisitivo dos professores. Uma carreira nebulosa projetava uma grande ansiedade nos formandos durante a trajetória de qualificação profissional. Formação precária em face do novo perfil do aluno e das condições de trabalho que se foram tornando deficientes determinaram um quadro severo na própria profissionalização.

Concomitantemente, na prática (porque na lei ainda existiam), os concursos públicos de títulos e provas foram rareando, e a nova geração de professores e professoras começou a ser contratada a título precário por meio de formas contratuais voláteis. E foram contratados de maneira mais rápida. Aquela formação inicial que garantia uma grande qualidade e o exame a que os professores eram submetidos para entrar no sistema público de ensino (que sempre representou até mesmo uma honraria para cada um) foi substituído por formas alternativas e precárias de recrutamento e seleção. Assim, aquela formação que se tinha nas universidades e nas tradicionais escolas normais, acabou sendo substituída por uma formação rápida, isolada e noturna apoiada na expansão de instituições superiores. Foi o meio rápido para as necessidades da expansão das redes dos sistemas. Esta urgência somada à "economia" de recursos determinaram, de modo geral, uma formação mais rápida e menos atenta, seja nas tradicionais escolas normais, seja nas licenciaturas ou nas faculdades de pedagogia.

Os novos contingentes populacionais provinham das camadas populares,

$\overline{190}$ Olhar de professor, Ponta Grossa, 7(1): 187-193, 2004. 
oriundas, em sua maior parte, de migrações em massa da zona rural ou de pequenas cidades do interior do país. Eram trabalhadores em potencial e esperançosos de uma vida melhor. Este perfil era novo, seja pelo tamanho do contingente, seja pelas adaptações culturais a serem processadas em suas vidas.

Com a entrada de novos perfis de alunos, os professores não estavam mais preparados para dar conta da diversidade sociocultural. E, por isso, entre outras razões, (não só porque nossa legislação previa então só quatro horas de aula por dia e cento e oitenta dias letivos) é que continua, também até hoje, a existência de problemas de repetência e de evasão. A formação inicial do professor nem sempre é adequada para a grande diversidade dos perfis populacionais das escolas. Por isso, a formação continuada é essencial.

Mas é preciso lembrar sempre que formação inicial é sempre algo absolutamente indispensável, já que é o subsolo e a infra-estrutura sobre os quais se erige um processo formativo continuado, capaz de articular essa formação inicial com as experiências profissionais, com os saberes advindos deste fazer e com os conhecimentos obtidos por cursos e programas presenciais ou virtuais. A certificação do docente, de caráter individual, a ser autenticada pelo Estado, é uma opção do professor.

Hoje, não se pode dizer que, substancialmente, o quadro situacional do docente tenha se alterado. Houve avanços no ordenamento jurídico, como no capítulo da Educação da Constituição Federal de 1988, muitos confirmados na LDB e exigidos novamente no Plano Nacional de Educação e na normatização do Conselho Nacional de Educação por meio de sua Câmara de Educação Básica. Muitos destes avançosforam incorporados pelas Constituições Estaduais e Leis Orgânicas Municipais e respectivas normatizações. No âmbito da formação docente, desenvolveram-se programas voltados para a atualização profissional por parte das secretarias de educação e por instituições de ensino superior. O volume de professores formados pela graduação e a pós-graduação cresceu e os recursos vinculados (e agora também sub-vinculados) à educação escolar retornaram, bem como a obrigatoriedade dos concursos públicos de títulos e provas para o cargo de docente nos sistemas públicos.

Entretanto, acrescentaram-se novas e urgentes exigências: o ensino médio é a nova (e feliz) "invasão" por parte das camadas que conseguem avançar para além dos oito anos de escolaridade obrigatória, A educação infantil impõe-se como necessidade educacional e social. A LDB criou modalidades importantes na educação básica, como a educação indígena, a educação de jovens e de adultos, a educação de pessoas com necessidades especiais. A formação docente é cada vez mais exigida pelos mecanismos externos e sistêmicos de avaliação. Veja-se, por exemplo, a insistência (imprescindível e necessária, mas não legalmente obrigatória) de nível superior para a educação 
infantil e para os quatro primeiros anos do ensino fundamental escalonada também no Plano Nacional de Educação. As exigências sobem, as expectativas crescem. O trabalho docente também aumenta, pois os projetos pedagógicos devem ser mais criativos na medida em que as Diretrizes Nacionais Curriculares não só extinguiram os currículos mínimos como postularam maior autonomia para os estabelecimentos escolares. Os salários continuam muito abaixo da dignidade do cargo e das crescentes exigências profissionais. Com um trabalho formalmente valorizado, mas na prática desprestigiado, nem sempre a área de educação consegue ser atrativa para os postulantes do diploma de ensino superior .

Por outro lado, não se pode ignorar os aspectos econômicos - tais como a fragilidade das contas externas, o parco crescimento econômico, o desemprego e a situação da própria previdência - que interferem na sustentabilidade do governo nacional e dos estados e municípios. A violência, por sua vez, tem atingido os espaços escolares. O medo entre docentes atuantes em escolas afastadas e isoladas é bastante expressivo.

Tudo isto implica a formação estendida para além dos bancos universitários como formação continuada, especialmente quando a educação a distância vem superando os espaços geográficos e os tempos escolares fixos.

Entretanto, é importante fazer uma distinção: na formação dos docentes, há elementos problemáticos que nascem do próprio processo dela e, por isso, estão nele; há outros contudo que interferem na formação e estão nela, mas que não nascem dela. Ignorar tais condicionantes é correr o risco de deslocar para o indivíduo e para a escola responsabilidades que não lhes são exclusivas. Nesse quadro, torna-se inadequado enfatizar a formação como a única e isolada saída de nossos problemas. Torna-se também complexo fazer da avaliação um instrumento de crescimento profissional, de exigência de mérito e de desempenho mais produtivo e mais compromissado.

Entretanto, a formação docente não pode deixar de enfrentar nem as urgências próprias da sociedade atual (com seu formidável entorno tecnológico) nem o compromisso com o resgate dos valores próprios do cidadão e da participação da educação escolar nestes desafios.

\section{Certificação}

Onde reside o fundamento da certificação?

Os sistemas públicos têm sua fundamentação mais profunda no direito de aprender do aluno. É desse cidadão em processo de formação para participar da vida pública que deriva o dever do Estado de propiciar o ensino de qualidade para todos. Portanto, não foi em função diretamente do dever do Estado que

$\overline{192}$ Olhar de professor, Ponta Grossa, 7(1): 187-193, 2004. 
se erigiram os sistemas públicos de ensino e sim em função do direito de aprender do estudante como cidadão. Esse direito, sem derrogar os princípios da diferença e da pluralidade, implica a garantia daquilo que é comum, universal, igualitário para todos. Os sistemas públicos têm de defender a gratuidade e a obrigatoriedade porque é o direito de aprender do estudante que lhe confere a autonomia para se tornar - progressivamente - nas suas distintas faixas etárias, um cidadão. É nessa permanente busca de um padrão de qualidade que se fundamenta a possibilidade de uma certificação que, por sua vez, faz jus aos saberes que o professor enquanto pessoa humana singular acumula e adquire pelos seus fazeres profissionais.

Surge, então, a possibilidade da certificação, ou seja, a capacidade do Estado, dos poderes públicos, de oferecer uma contínua qualificação e formação, para que, nessa formação, os professores tenham reconhecidas duas fontes de conhecimento, além da obtida na formação inicial: uma, que é sua - os saberes nascidos dos seus fazeres e de sua iniciativa e que precisam ser organizados; e a outra, - aquilo que a universidade conquistou e fez avançar pela pesquisa, pela pós-graduação e cujos produtos se estendem pelo ensino. Estes momentos de aprendizado representam uma nova forma de qualificação do professor, desde que haja uma instância capaz de oferecer as condições propícias de sua realização e de autenticar a opção do sujeito de submeter-se a uma avaliação certificadora de seus avanços.

Desse modo, pensar a formação contemporânea, polivalente, crítica e compromissada de docentes em exercício profissional na educação básica representa um desafio que vai além do processo formativo inicial. Na medida em que o zelo para com os servidores, em termos de prestígio e de atualização, é responsabilidade dos poderes públicos, a formação continuada representa uma obrigação com clara sustentação legal. A certificação representa uma opção voluntária do próprio docente pela busca de reconhecimento do seu mérito profissional. 